\title{
Situs Wonoboyo : Pemukiman Kuna Pada Jenjang Mana?
}

\section{Bugie Kusumohartono}

Keywords: chronology, settlement, Hindu-Buddha, archaeology

\section{How to Cite:}

Kusumohartono, B. Situs Wonoboyo : Pemukiman Kuna Pada Jenjang Mana?. Berkala Arkeologi, 13(3), 47-58. https:// doi.org/10.30883/jba.v13i3.616

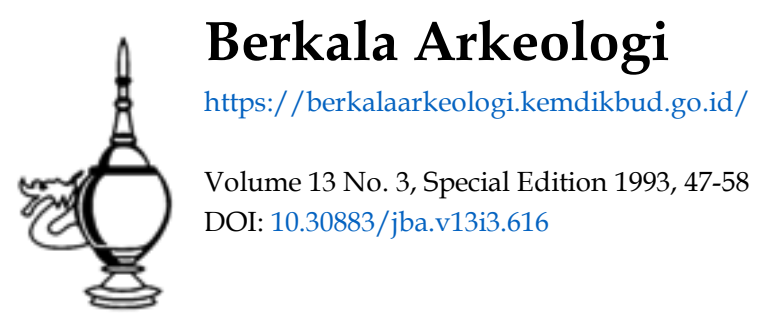

\section{(c) (i) 8 (2)}

This work is licensed under a Creative Commons Attribution-NonCommercial-ShareAlike 4.0 International License. 


\title{
SITUS WONOBOYO \\ PEMUKIMAN KUNA PADA JENJANG MANA?
}

\author{
Oleh : \\ Bugle Kusumohartono
}

\section{Permasalahan}

Daerah dengan elevasl 150-170 meter dpl. di sekltar Sungal Opak - terutama dl sebelah timur Sungal Kuning (Sleman) dan dl sebelah barat Sungal Wedi (Klaten) - merupakan kawasan dengan tinggalan arkeologlk yang sangat tinggl. Berbagal situs upacara yang berslfat monumental dari sekltar abad ke-9 Masehl terpusat di sinl, dan secara sepintas terlihat adanya dominasl Budhlsme dl sini. Dalam kaitan itu dapat ditunjukkan di sini beberapa cuplikan yang merionjol, yaltu Candi Kalasan, Candi Sari, Candi Sewu, Candi Plaosan, Candi Lumbung, Candi Sojiwan, dan lain sebagainya.

Namun demikian beberapa fasllitas upacara beraliran Siwalsme - walaupun dalam intensitas yang lebih rendah - juga didapati di kawasan tersebut, misalnya candi Prambanan, candi Sambisari, dan ceberapa candi lain di Dataran Tinggi Baka. Khusus mengenal Candi Prambanan, menurut Sejarah Nasional Indonesia II, pendiriannya didahului oleh peperangan antara Rakai Pikatan melawan musuh (Rakai Walalng Pu Kumbhayon(?), yang dimenangkan oleh Rakai Pikatan. Setelah memenangkan pertempuran, diresmlkanlah bangunan sucl untuk dewa Siwa (S/wagrha) serta memindahkan kekuasaan polltik ke anaknya, yaltu Rakal Kayuwangl dyah Lokapala (Sumadlo, 1984 : 125-33).

Pada peta arkeologi Jawa tengah, kawasan Prambanan adalah lokasl yang menylmpan tinggalan bangunan upacara paling tinggl Intensitasnya. Keleblhan litu dapat dinllal balk darl ukuran rata-rata bangunannya, kerapatannya, ragam keagamaannya, kompleksltas teknologl, maupun tIngkatan estetlkanya. Pada corak budaya serupa di Asla Tenggara daratan, lokasl pusat-pusat keglatan upacara utama masyarakat biasanya berhimplt dengan lokasl pusat-pusat kehtdupan polltlk (Kusumohartono, 1989; Soekmono, 1974). Gagasan In! terdukung oleh cerlta tradlsl mengenal Keraton Ratu Boko, yang dlidentlikaslkan pada tinggalan arkeologlk ol atas Bukt Boko kurang 
leblh 2 kllometer lurus di sebelah selatan Candl Prambanan.

Kurang lobih $3 / 4$ Ilomegter dl sebolah timur Sungal Wedi terdapat Sltus Wonoboyo, atau tepatnya termasuk dalam adminlstrasi Dusun Plosokuning. Desa Wonoboyo, Kecamatan Jogonalan, Kabupaten Klaten, Jawe Tengañ. Berdasarkan konsentrasinya, di situs ini dijumpaj dua kelompok temuan arkeologik. Pertama, adalah tinggalan arkeologik berupa sisa pemuklman kuna (Anonim, t.th.: 80) yang secara umum berada dl bawah Dusun Plosokuning sekarang. Kedua, adalah artefak emas seberat $32 \mathrm{~kg}$ dl tepl sungal yang berjarak sekitar 90 meter dl sebelah timur sisa pernukiman kuna yang disebutkan pertama. Adalah benar apablla Kusen (1991: 1) mengidentiflkaslkan tinggalan artełak emas tersebut memiliki fungs। sebagai regalia atau emblems of royaity pada jamannya.

Pada umumnya para pengamat maupun pakar yang terlibat dalam penanganan Situs Wonoboyo mengasosiasikan keberadaan pemuklman kuna di bawah Dusun Plosokuning dengan deposit artefak emas tersebut

Adanya temuan emas dalam jumlah yang sangat besar sebelum dilakukannya penelitian Ini dapat memberlkan gambaran tentang stratifikasi sosial masyarakat yang menghuni situs tersebut. Temuan bemilai tinggl itu tentunya dapat menjadl bukt bahwa penghuni situs Wonoboyo mempunyal status soslal yang. tinggi, bahkan mungkin raja (ibld.).

Secara leblh konkrit Situs Wonoboyo dinllai memilikl kemungkinan pernah berfungsi sebagal lokasi keraton atau pusat pemerintahan kerajaan Matam kuna (Subroto, 1991).

Namun sebagaimana telah dlsampaikan di atas, maka apablla dicermatt akan terlihat bahwa sebenarnya asoslasi antara pemukiman kuna dengan artefak emas tersebut memperlihatkan beberapa keraguan. Ekskavasi arkeologlk dan penelltlan geomorfologlk menegaskan adanya batas berupa pagar artifislal dl tepi timur pemukiman kuna tersebut. Di area di sebelah timur pagar tersebut, ... probabilltas periemuan data arkeologis, terutama artefaktual, akan relatif kecll. Mungkin sekall baglan Inl sudah berada di tuar kawasan keglatan (activitly area) (Anonlm, t.th.: 81) ...

Temuan artefak emas dalam Jumlah yang relatlf besar pada konteks pemukiman kuna memang pernah dljumpal, misalnya dl Sltus Trowulan. Jawa Timur. Kondisi Itu merupakan salah satu faktor yang 
menyebabkan masyarakat mengldentlflkaslkan Situs Trowulan sebagai bekas lbukota kerajaan Majapahlt. Namun bagi situasi di mana temuan $32 \mathrm{~kg}$ artefak emas Situs Wonoboyo secara obyektlf tidak berada dalam konteks sisa pemukiman kuna di sebelah baratnya .. dengan kata lain identifikasi pemuklman kuna tersebut sebagai bekas pusat kekuasaan politik atau lokasi lbukota kerajaan semakin diragukan -. maka menjadi menarik untuk menelaah letak pemukiman tersebut dalam pola jenjang pemukiman masa lalu.

\section{KERANGKA KONSEPTUAL}

Masyarakat dengan corak budaya Indonesia kuna (Hindu/Budha) adalah masyarakat berlapis (stratifeid) yang terstruktur ke dalam organisasi sosial yang kompleks, khususnya secara vertikal. Stratiflkasi masyarakat masa lampau tercermin pada kesenjangan wewenang yang secara keruangan dapat dikaji melalui studi pola pemukiman (Chang, 1972; Willey, 1956).

Menurut Flannery (1976), suatu karakter khas darl masyarakat berlapis dicirikan oleh pemukimannya yang teratur dalam hirarki atau jenjang. Secara keruangan makro, hirarkl tersebut tercipta dalam pola sejumlah besar pemukiman kecil dan sejumlah kecil pemukiman yang lebih besar. Prinsip studi semacam itu berada dalam model studi Jaringan pusat-pusat (central-place moded) dan analisls kesenjangan jenjang-ukuran (rank-size analysis). Konsep pokok yang dioperasionalisasikan dalam menganalisis hirarki pola pemukiman adalah (Paynter, 1983) :

1. Faktor fungsl ekonomik darl suatu pemukiman, dan

2. Faktor hambatan jarak dalam jaringan pemukiman.

Fungsl ekonomlk mendapatkan perhatlan khusus dalam telaah Inl karena kewenangan administratif-polltlk pada masa Indonesia kuna, khususnya di Jawa, berlmplt dengan kewenangan ekonoml. Artinya, mekanisme perekonomlan negara yang dljabarkan pada pola distrlbusl dan redlstrlbusl (pertukaran) komoditas perdagangan berada terpusat dl tangan kelas penguasa (Kusumohartono, 1985; 1991).

John N. Miksle (1984) menambahkan bahwa pertukaran 
tersebut tidak selalu berupa bahan, namun juga berupa informasl dan tenaga. Walaupun obyek yang dlpertukarkan cukup luas, namun Paynter (1983) tetap memasukkanya dalam kategorl fungsl ekonomlk dalam studi tentang jenjang pemukiman. Dan dalam studinya. Miksic (1984) memperoleh gambaran bahwa tinggi-rendahnya fungsi ekonomlk dapai ditafsirkan berdasar pada jumlah ragam keglatannya. Semakin beragam jenls kegiatan dalam pemukiman, maka semakin tinggi hirarkinya. Di lain plhak, semakin tinggl fungsi ekonomlk dan ragam kegiatannya, secara fisik akan semkin luas pula situs pemukimannya.

Prosedur untuk mengalokasikan fungsi-fungsi ekonomik ke berbagal tempat blasanya didasari oleh pengaruh kesenjangan jarak. Karena kaitan antara Jarak dan pengeluaran energi merupakan pertimbangan yang penting (Miksic, 1984), maka hanya sebaglan pemukiman yang akan menjadi pusat-pusat dari jarlngan di mana pusat-pusat tersebut memlliki tingkat pencapalan yang paling efislen bagi pemuklman-pemukiman lain di sekitarnya. Di lain plhak pusatpusat jaringan tersebut memiliki ragam keglatan yang lebih tinggi daripada sekltarnya (Paynter, 1983).

\section{TELAAH JENJANG PEMUKIMAN}

Dengan memperhatlkan gambaran di atas maka cukup menjadi jelas bahwa model jaringan pusat-pusat dan anallsis kesenjangan jenjang-ukuran sangat potensial untuk menjawab masalah tentang kedudukan pemuklman kuna Wonoboyo dalam hirarkl pemukiman masa lampau. Sebagai ibukota misalnya, pemukiman kuna Situs Wonoboyo akan berada pada puncak jenjang jaringan pemukiman. Secara hipotetik Situs Wonoboyo harus memllikl fungsl ekonomik yang paling besar, dalam bentuk ragam aktivitas paling tinggl dan ruang situs paling luas, serta jarak yang pallng eflsien dari pusat-pusat pemukiman yang lebih rendah dl sekitarnya.

Sumber-sumber sejarah. darl Jaman Indonesia Kuna memberlkan gambaran bahwa wilayah polltlk kerajaan terdirl atas daerah pusat kerajaan (Ibukota) di mana istana raja berada, daerahdaerah watak, dan daerah-daerah wanua (Sumadio, 1984:190). Wanua adalah kesatuan polltlk terkecll yang diplmpln oleh sekelompok pemuka desa (rama). Mencakup beberapa wanua adalah watak. yang 
dipimpin oleh rakal atau pamgat. Kajian secara khusus atas prasasii jaman Mataram Kuna misalnya, berhasil menghimpun sekitar 101) nama watak dan lebih banyak lagi nama wanua.

Namun dalam kenyataannya dapat dikatakan bahwa kajian secara fisik atas jaringan pemukiman masa Indonesia kuria sungguh sulit dilakukan mengingat sangat sedikit situs habitasi jang dapat dljumpai hingga saat ini Dari situs-situs habitasi yang dapat diteliti secara fisik sanga! suli: pula untuk mengidentifikasikannya dengan toponimı pemukimari yang tersurat pada data tekstual (Wibowo. 198.). Beberapa conton dari kasus sedemikian itu di antaranya adalah di Situs Wonoboyo (Klaten), Siłus Medowo (Sidoarjo), Situs Trowulan (Mojokerto). Situs Caruban (Lasem), serta Situs Biting (Lumajang).

Di lain pihak sungguh tidak mudah mengidentifikasikan toporimi kuna pada pola toponimi sekarang tanpa didukung penelitian lapangan yang intensif (Kusen, 1991). Sehingga penelitian arkeologi dengan menerapkan model jaringan pusat-pusat dan analisis kesenjangan jenjang-ukuran akan menjadi sulit untuk dioperasikan secara ideal untuk dalam kaitan untuk melihat letak pemukiman Wonciboyo kunia dalam hirarki jaringan pemukiman masa lampau.

Satu-satunya jalan yang dapat dicobakan di sini adalah membandingkan Situs Wonoboyo dengan situs-situs pemukiman lain, walaupun dalam Jaringan yang mungkin berbeda. Walaupun kemungkinan berbeda, namun sekurangnya pemukiman yan! dlperbandlngkan berasal dari fase yang sama. Sepert diketahu! sampel arang dljumpai di dalam ekskavasi penyelamatan tahap III

... Temuan yang ada dl beberapa kotak ekskavasi menunjukkan arang berasosiasi dengan temuan gerabah atau unsur bangunan. Berdasarkan konteks temuannya itu dapat dlduga bungkah-bungkah kecll arang tersebut adalah aklbat aktluitas manusla. Hanya saja kegiatan apa yang meninggalkan ekofak tersebut masih sulli diketahul. Secara potenslal s/sa-s/sa arang tersetut dapat diporgunakan untuk menentukan portanggalan dan usaha untuk analisis C-14 sedang diusahakan (Anonlm, t.th. : 74).

Menurut hasll Laboratorlum Kimla Nuklir dan Proses PPINY. BATAN, sampel arang tersebut menunjukkan pertanggalan abad $k$ k XIV-XV Masehl (Informasl pribadi darl Ir. Haryono Arumblnang M.Sc. dan Drs. Wisjachuddin Faisal). Oleh karena itu perbandingan dilakukan 
meliputi situs-situs pemukiman sekitar fase litu Jawa (tengah dan timur). Beberapa sltus pemukiman yang digunakan sebagal parameter pembanding adalah Situs Medowo (Sidoarjo) darl abad XIII-XIV. Situs Caruban (Lasem) dari abad XIII-XVII, Situs Biting (Lumajang) dari abad XIV-XVII, dan sedapat mungkin juga Situs Trowulan (Mojokerto) darl abad XIV. Memang tidak dapat dlbuktlkan bahwa situs-situs tersebut berada dalam satu Jaringan pemukiman dengan Wonoboyo kuna, namun juga tldak ada data yang signifikan menyatakan sebaliknya.

Berikut Inl disalikan matriks yang menggambarkan ragam tinggalan arkeologik sekallgus ragam kegiatan dl berbagal situs dalam perbandingan 


\begin{tabular}{|c|c|c|c|c|c|}
\hline Ragam Artotak / Keglatan & Wnb & Mdw & Crb & Big & Trw \\
\hline 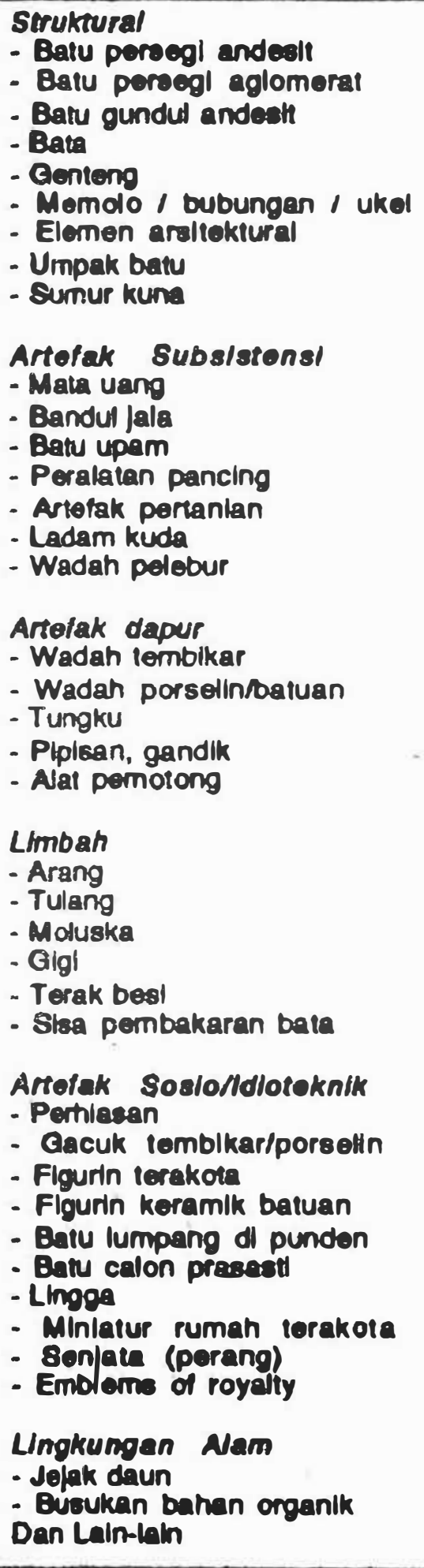 & + & $\begin{array}{l}+ \\
+ \\
+ \\
+ \\
+ \\
+ \\
+ \\
+\end{array}$ & $\begin{array}{l}+ \\
+ \\
+ \\
+ \\
+ \\
+ \\
+ \\
+\end{array}$ & $\begin{array}{l}+ \\
+ \\
+ \\
+ \\
+ \\
+ \\
+ \\
+ \\
+ \\
+ \\
+ \\
+ \\
+ \\
+ \\
+ \\
+ \\
+ \\
+\end{array}$ & $\begin{array}{l}+ \\
+ \\
+ \\
+ \\
+ \\
+ \\
+ \\
+\end{array}$ \\
\hline & 8 & 24 & 21 & 26 & 96 \\
\hline
\end{tabular}

Darl keragaman aktivitas yang terlihat pada matriks ol atas, 
maka dapat diperoleh gambaran bahwa sekurangnya ada tlga kelas pemukiman pada sekitar abad XIII-XVII, yaltu kategorl pemukiman tingkat I diwakill oleh Situs Trowulan, kategori pemukiman tingkat II diwaklli oleh Situs Biting, Situs Medowo, dan Situs Caruban, serta kategori tingkat III diwakili oleh Situs Wonoboyo.

Apabila dihubungkan dengan luas ruang fisik yang mewadahi berlangsungngya fungsi-fungsi ekonomik tersebut, perlu kiranya diperhatlkan matriks di bawah ini :

\begin{tabular}{|l|r|}
\hline \multicolumn{1}{|c|}{ Nama Situs } & Luas \\
\hline 1. Wonoboyo & $1,5 \mathrm{Ha}$ \\
2. Caruban & $24 \mathrm{Ha}$ \\
3. Medowo & $42 \mathrm{Ha}$ \\
4. Biting & $135 \mathrm{Ha}$ \\
5. Trowulan & $12.400 \mathrm{Ha}$ \\
\hline
\end{tabular}

Dari gambaran pada matriks di atas nampak jelas bahwa fenomena hirarki pemukiman pada abad XIII-XVII dl Jawa terdukung oleh fakta mengenai luas ruang fisik dari masing-masing situs pemukiman. Semakin tinggi cakupan fungsi ekonomik dari suatu pemukiman berarti pula semakin luas ruang fisik pemukimannya

Apabila diperhatikan pada peta, maka terlinat bahwa Situs Trowulan berada kuranglebih di pusat kawasan Jawa timur, di mana kawasan tersebut dipercayai sebagai pusat kehidupan budaya klasik antara abad ke XI-XVII. Sementara itu Situs Wonoboyo berada pada bagian tepi wilayah peradaban Hindu/Budha masa itu, yang secara politik berada di bawah kewenangan kelas penguasa Majapahit.

Sesuai dengan prinsip model studi jaringan pusat-pusat dan analisis kesenjangan jenjang-ukuran, Ibukota atau pemukiman tingkat I berada pada lokasi yang paling efisien, untuk dicapai dari berbagai pemukiman di sekitarnya, bagi proses pertukaran energi, bahan, dan informasi. Dengan membandingkan lokasi dari lima situs pemukiman tersebut di dalam konstelasi jaringan pemukiman kuna di Jawa abad XI-XVI, maka ditafsirkan bahwa lokasi Trowulan memang paling efisien. Sebaliknya lokasi Wonoboyo terhitung paling tidak efisien, 
1. Pengumpulan data dasar dan Informasl Instansional.

2. Observasi dan Inventarlsasl lapangan.

3. Penentuan tujuan/prioritas pengelolaan.

4. Zonasi unit pengelolaan.

5. Pengembangan sumberdaya arkeologls, yang mencakup:

a. penelitian dan pemantauan,

b. pemugaran,

c. perilndungan,

d. pemaniaatan, dan

e. evaluasl.

Tiga kegiatan pertama merupakan tahap perencanaan, kegiatan keempat merupakan tahap pelaksanaan, dan kegiatan kelima termasuk tahap pengembangan.

Data dasar dan informasi Instansional yang dikumpulkan meliputi berlta/artikel dari media massa, artikal dari journal, data dari literatur, peta (topografi, geologi, penggunaan lahan, ikim, tanah, dan tematik lainnya), foto wjara, citra satelit, seria publikasi (daia iklim dari Stasiun Blimatologi Lanuma Adisucipto, kependudukan, sosial okonomi, atau data darl Bips lalnnya). Data dasai iersebut merupakan masukan yang sảngat Dermanfaał unł̌k mengeianui kondisi fisik Slitus Wonoboyo, sehingga akan memudahkan dalam kegiatan observasi dan inveniarisasi di lapangan.

Masukan yang diperlukan dalam observasi dan inve्sntarisasi adalah temuan dari penduduk, informasl dari masyarakat sekitar, wawancara dengan tokoh masyarakat atau perangkat desa, dan kemudian dilakukan ekskavasi. Berdasarkan data dasar dan hasil ekskavasi ditentukan prioritas yang akan dikelola. Hal ini harus dilakukan zonasi unit-unit pengelolaan untuk memudahkan dalam melaksanakan pengelolaan.

Unit-unit pengelolaan ltu dapat berupa unit konsentrasi penemuan perhiasan mas, unit bangunan kuno, dan unlt persebaran artefak lainnya. Setelah mengetahul unit-unit tersebut akan memudahkan dalam melaksanakan pengembangan sumberdaya arkeologls. Keglatan pengembangan inl meliputl penelitian dan pemantauan. Dengan demlkan perlu dibentuk dua tim, yaltu tim penelltlan dan tlm pemantauan. Hasll penelltlan akan digunakan dasar pemugaran. 
Jika pemugaran telah selesal, diusahakan adanya perlindungan balk darl segl peraturan (Keppres No.32/1990 tentang Kawasan LIndung, UU Cagar Budaya) maupun dari segi fisik. Dengan adanya perlindungan, maka Situs Wonoboyo dapat dimanfaatkan sebagal cagar budaya atau pusat keglatan penelitian/pariwlsata, dengan catatan bahwa semuanya itu telah dilakukan evaluasi. Umpan balik akan cillakukan, jika hasil evaluasi tidak balk. Umpan balik itu dapat bersifat pendek dan dapat bersifat panjang bergantung pada letak ketidakberesannya.

Keluaran atau hasil yang diperoleh adalah bahwa Situs Wonoboyo periu dimasukkan ke dalam cagar budaya. Hal inl menglngat, bahwa:

1. Kawasan temuan perhlasan emas terletak di kawasan sempadan sungal (kawasan lindung, menurut Keppres No. 3211990).

2. Kawasan Wonoboyo sermasuk kawasan yang relatlf subur, sehingga perkembangan permukiaman akan leblh cepat darlpada penelitian arkeoiogi.

3. Kawasan Wonoboyo termasuk kawasan yang rentan terkena bencana alam, baik berupa bencana vulkanik (atiran lahar) maupun bencana gempa bumi.

\section{KESIMPULAN}

1. Secara geomorfologis, Situs Wonoboyo terletak di dataran aluvial kakl gunungapl Merapl, sehingga tanahnya subur, mudah memperoleh air, mudah memperoleh bahan bangunan. Hal Ini menjadlkan kawasan Wonoboyo sangat cocok untuk bermukim dan bertani.

2. Ditinjau darl struktur geologinya, Situs Wonoboyo yang terletak dl kakl gunungapi Merapl merupakan kawasan yang rawan terhadap gempa buml, karena Gunungapi Merapl terletak dl persilangan antara sesar mellntang yang arahnya Utara-Selatan dan sesar membujur yang arahnya Barat-TImur.

3. SHus Wonoboyo terletak dl sekltar daerah bahaya II Gunungapl Merapi, sehingga kawasan Inl rentan terhadap bencana aliran lahar, sepertl yang terbuktl dengan terimbunnya situs inl oleh endapan lahar hasil letusan Gunungapl Merapl pada tahun 1006.

4. Berdasarkan pengamatan pedostratigrafl, tebal endapan lahar 
sementara itu tiga sltus pemukiman kuna yang lain berada pada kategori di antaranya

\section{KRISTALISASI GAGASAN}

Merujuk pada diskusi di atas, diperoleh gambaran ripotetik bahwa pemukiman Medowo kuna merupakan sampel dari pemukiman pada jenjang ketiga. Dalam hirarki jaringan pemukiman masa klasik pemukiman jenjang ketiga diidentifikaslkan sebagal wanua. Permasalahan lanjutan yang muncul adalah, apakah nama asli semula dari wanua dl bawah Dusun Plasakuning tersebut.

Karena tertutup oleh material vulkanik (lahar). maka wanua tersebut cukup terpreservasi. Penemuan wanua kuna dalam keadaan "utuh" merupakan asset budaya yang langka. Oleh karena ltu tindakan penelitian dan ekskavasi yang diselenggarakan di atasnya haruslah selektlf, dilandasi oleh permasalahan / kerangka / model yang matang. Dengan demlklan akan selalu tersedla peluang bagi gagasan penelitian yang matang dan semakin sempurna, untuk diujikan di Situs Wonoboyo pada masa-masa mendatang.

Dengan hipotesls bahwa Situs Wonoboyo berada pada jenjang wenue, maka semakln kuat keraguan terhadap asoslasi fungsionalnyanya dengan deposit temuan $32 \mathrm{~kg}$ artelak emas yang ditemukan dl tepl sungai dl sebelah timurnya. Dapat dynyatakan bahwa tidak terdapat kesejajaran balk secara soslal maupun ekonomlk antara kelas masyarakat pemuklm wanu\& Wonoboyo kuna dengan regalla atau emblems of royalty tersebut. Masalah bagaimana menjelaskan kehadiran artefak emas tersebut di tempat penemuannya pada tahun 1990, itu soal lain lagl.

Selain ketldaksejajaran jenjang soslal-ekonomi antara pemuklman kuna dan artefak emasnya, keraguan atas asosiasi fungsional keduanya diperkuat oleh perbedaan pertanggalannya. DIkatakan di atas bahwa pemukiman kuna Wonoboyo berasal darl sekitar abad XIV-XV, sedang berdasarkan atas gaya seni hlasnya diperkirakan artefak emas tersebut berasal darl sekltar abad Vill-X (Haryono 1991. 7-8)

Memperhatlkan kallan yang dllakukan oleh Kusen (1991), dapat dipastikan bahwa warmus-wanua semacam pemuklman Medowo kuna 
pernah hadir intensif di kawasan ini. Sebaglan sudah tidak berbekas lagl karena dalam rentang waktu yang panjang totap berfungsl sobagal pemukJman (desa) sampal dengan saat Ini. Sementara the sebaglan kecll yang lain masih terpreservast di bawah laplsan lahar, sobagaimana halnya Situs Wonoboyo.

PemukJman kuna di tangoul alam sungal semacam Medowo, merupakan pola yang blasa dijumpal dl Jawa. Pada Doborapa sungal yang mengallikan lahar gunungapl kemungkinan masih akan banyak dijumpal sttus-sltus pemukiman darl masa Indonesia kuna dl bawah permukaan tanah tanggul alam sungainya. Di satu plhak oksplorasl penolttian pemuklman kuna dapat dlpersemplt ko cirl-cirl bentang goomortologlk semacam ltu, di lein plhak sogala keglatan pombangunan masa kinl dl kawesan tanggul alam sungal pengantar lahar perlu dlcermatl agar tidak meruglkan keberadaan situs arkeologi di bawahnya. 


\section{KEPUSTAKAAN}

Anonim. t.th. Laporan Keglatan Penentuan Batas Wilayah Cagar Budaya Dalam Rangka Penyelamatan Situs Wonoboyo. Bakosurtanal. Ditlinbinjarah, dan Fakultas Geografi UGM.

Chang, , K.C. 1972. Settlement Patterns in Archaeology, AddisonWesley Module in Anthropology No. 24. Reading, Mass. Addison-Wesley Publ. Co.

Flannery, K.V. 1976. Evolution of Complex Settlement Sysiems, dalam K.V. Flannery (p̈eny.) The Early Mesoamerican Village. New York: Academic Press.

Haryono, TImbul. 1991. Benda-benda Emas darl Wonoboyo (Klaten): TInjauan Tentang Fungsl dan Pertanggalannya. Makalah sarasehan di Kabupaten Klaten 5 September 1991.

Kantor Suaka Peninggalan Sejarah dan Purbakala Proplnsi Jawa tengah dan Jurusan Arkeologi Fakultas Sastra UGM. 1990a. Laporan Ekskavasl Penyelamatan Sltus Wonoboyo. 5-9 Nopember 1990.

Kantor Suaka Penlnggalan Sejarah dan Purbakala Propinsi Jawa tengah dan Jurusan Arkeologi Fakultas Sastra UGM. 1990 b. Laporan Ekskavasi Penyelamatan Sltus Wonoboyo. 10-19 Desember 1990.

Kusen. 1991. Identifkasi Toponim Dalam Prasesti Jawa Kuna Abad IX-X Darl Prambanan dan Sekltarnya dengan Toponim Masa KInI, Rapat Anallsls Sumber Tertulls Masa Klaslk Trowulan, 18-23 November 1991.

Kusumohart.ono, B. M. (1985). St.rat.egi Adapt.asi Lingkungan, Pola Ekonomi, Dan Pelest.arian Kekuasaan, Paparan Mengenai Beberapa Dat.a Jaman Indonesia Kuna. Berkala Arkeologl, 6(2), 33ç47. ht.t.ps:II dol.org/1 0.30883/jba.v612.442

Kusumohartono, Bugle. 1989. Agroekosistem Sawah Pada Masa Urban Awal al Asla Tenggara, Pertemuan IImlah Arkeologl. V. Ikatan Anll Arkeologl Indonesla.

Kusumohartono, Bugle. 1991. Konsepsl Ble Men Dalam Kehldupan Sosial-Pollttk Indones/a Kuna, Rapat Anallais Sumber 
Tertulis Masa Klasik Trowulan, 18-23 November 1991. Miksic, J. N. (1984). PENGANALISAAN WILAYAH DAN PERTUMBUHAN KEBUDAYAAN TINGGI DI SUMATRA SELATAN. Barkala Arkaologl, 5(1), 9ç24. hllps://dol.org/10.30883/jba.v5l1.263 Paynter, Robert W. 1983. Expanding the Scope of Settement Analysis, dalam James A. Moore dan Arthur S. Keene (peny.) Archaeological Hammers and Theorles New York Academic Press.

Soekmono. 1974. Candl Fungsi dan Pengertiannya. Disertasi Universitas Indonesla.

Subroto, Ph. 1991. Benarkah Wonoboyo Bekas Sobuah Keraton?. Makalah sarasehan dl Kabupaten Klaten 5 September 1991.

Sumadio, Bambang, dkk. (peny.). 1984. Jaman Kuna, dalam Marwati Djoened Poesponegoro dan Nugroho Notosusanto (peny.). Sojarah Nasional Indonesla, II. Jakarta: PN Balal Pustaka.

Wibowo, A.S. 198. Kubur Panggung ......., Malalah Arkeologi,...... Lembaga Arkeologi FSUI.

Willey, G.R. (peny.) 1956. Prehistoric Settlement Patterns in the New World, Viking Fund Publication on Anthropology No. 23. 